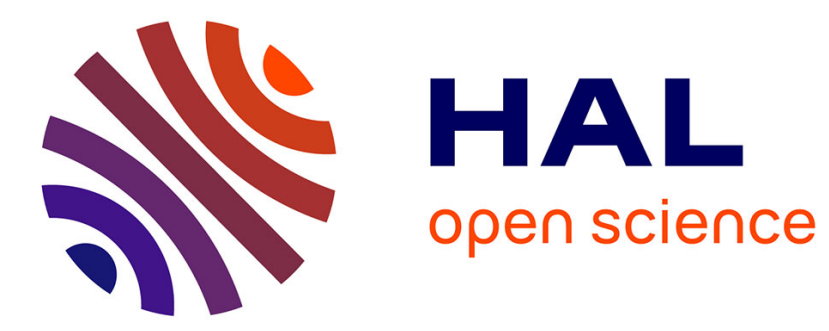

\title{
Combining glass cutting and edge shaping by using optical Airy beams
}

David Sohr, Jens Ulrich Thomas, Bernd Hoppe, Stefan Skupin

\section{To cite this version:}

David Sohr, Jens Ulrich Thomas, Bernd Hoppe, Stefan Skupin. Combining glass cutting and edge shaping by using optical Airy beams. Laser Applications Conference (LAC), Oct 2021, Optica Virtual Event, United States. 10.1364/LAC.2021.LW3B.1 · hal-03372782

\section{HAL Id: hal-03372782 \\ https://hal.science/hal-03372782}

Submitted on 11 Oct 2021

HAL is a multi-disciplinary open access archive for the deposit and dissemination of scientific research documents, whether they are published or not. The documents may come from teaching and research institutions in France or abroad, or from public or private research centers.
L'archive ouverte pluridisciplinaire HAL, est destinée au dépôt et à la diffusion de documents scientifiques de niveau recherche, publiés ou non, émanant des établissements d'enseignement et de recherche français ou étrangers, des laboratoires publics ou privés. 


\title{
Combining glass cutting and edge shaping by using optical Airy beams
}

\author{
David Sohr ${ }^{1,2}$, Jens Ulrich Thomas ${ }^{1}$, Bernd Hoppe ${ }^{1}$, Stefan Skupin ${ }^{2}$ \\ ${ }^{1}$ SCHOTT AG, Hattenbergstrasse 10, 55122 Mainz, Germany \\ ${ }^{2}$ Institut Lumière Matière, UMR 5306 Université Lyon 1 - CNRS, Université de Lyon, 69622 Villeurbanne, France \\ david.sohr@schott.com
}

\begin{abstract}
Using an optical Airy beam we created curved permanent modifications in borosilicate glass and achieved separation of a $525 \mu \mathrm{m}$ thick glass sheet with a convex edge with a radius of curvature of $774 \mu \mathrm{m}$ after etching. (C) 2021 The Author(s)
\end{abstract}

For reasons reaching from practical purposes, such as improved handling and durability, to decorative considerations, processed glass is often required to have a seamed or round edge. Currently this requires an extra grinding step to obtain for example the most common curved shape, the so called "c-cut". For the preceding processing step of cutting the glass to shape, ultra short pulse lasers with their beams shaped to an elongated focal volume (line focus) are increasingly replacing conventional cutting tools $[1,2]$. These straight line foci can be used to modify the workpiece throughout its entire depth with one single laser shot, effectively perforating it instantaneously, instead of having to dig into the material, as for example by ablation [3]. This way single pass laser glass cutting up to a thickness of $12 \mathrm{~mm}$ has been demonstrated with a Bessel-like beam [2]. Here, we report on combining cutting and edge shaping of glass in one laser process. To this end, we replace the Bessel-like beam in the aforementioned micromachining setup with an Airy-Gauss beam to directly achieve a curved edge as the result of the cutting process. We used a $2 \mathrm{f}$ setup as shown in Fig. 1 a), imaging the cubic phase produced by a diffractive optical element (DOE) with a microscope objective (MO) to create an Airy-Gauss beam. The main lobe of this beam appears to be accelerated in the transverse plane during propagation, yielding a curved line focus with a parabolic trajectory in the longitudinal plane, see Fig. 1 b). While the cubic phase mask was fixed in our experiments, we used the focal length $f$ of the microscope objective for scaling the line focus $[4,5]$.

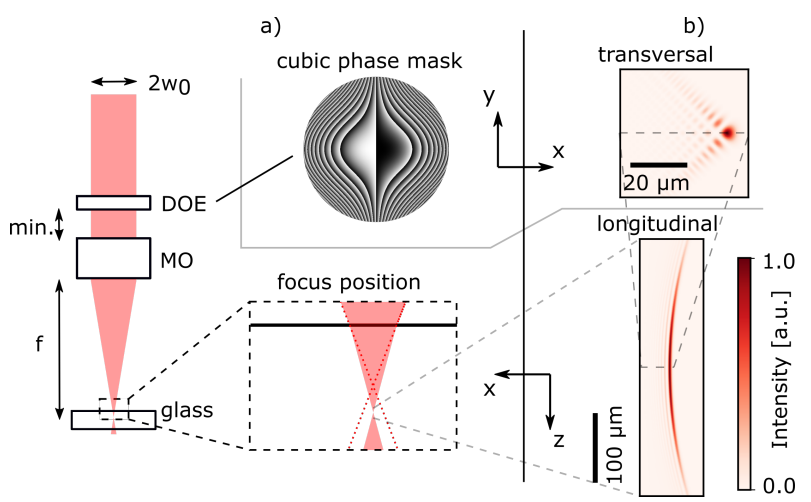

Fig. 1. Experimental 2f-setup (a) used for creating an Airy-Gauss beam and resulting theoretical intensity profiles (b) for focal length $f=10 \mathrm{~mm}$.

We found that the volume modifications resulting from placing the focus deep within a glass sheet show the expected curvature for a wide range of experimental parameters (see Fig. 2 a)). With increasing pulse energy the trajectory remains unchanged while the length and lateral extent of the modifications increase, for $f=20 \mathrm{~mm}$ reaching lengths of up to $2 \mathrm{~mm}$ and a maximum angle $a_{\max }=11^{\circ}$. More confined and stronger modifications are observed for longer pulse durations. Simulations of the energy deposition employing an unidirectional pulse propagation model accounting for all relevant nonlinear propagation effects, in particular the laser-generated conduction electrons [6], corroborate this observation: For the short pulses the laser affected zone is much broader due to intensity clamping, resulting in high absorption, but a low energy confinement. The broadening of the modification is reinforced due to the low focal contrast between the main lobe and the side lobes of the Airy beam. 
This low contrast is particularly important near the glass surface when perforating glass sheets, as the threshold for laser induced damage is higher in volume than at the surface. We found that an intermediate pulse duration of $5 \mathrm{ps}$ in combination with a burst mode operation emitting 2 pulses with a delay of $25 \mathrm{~ns}$ per burst results in low surface damage while still creating a sufficiently strong volume damage throughout the glass sheet. With these laser parameters we achieved single pass perforation of a $525 \mu \mathrm{m}$ thick glass sheet for $f=10 \mathrm{~mm}$. Using a well established etching process with potassium hydroxide [7] allowed us to separate the glass along a perforation line, thus obtaining a well defined convex edge down to a radius of curvature of $774 \mu \mathrm{m}$ as shown in Fig. 2 b).

a)

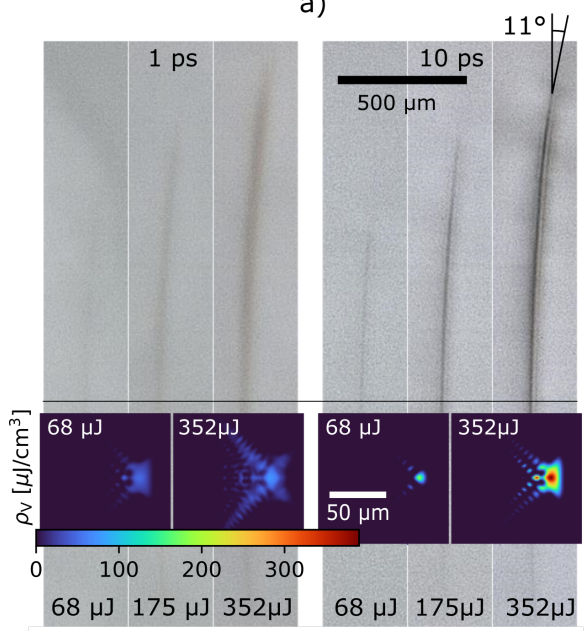

b)

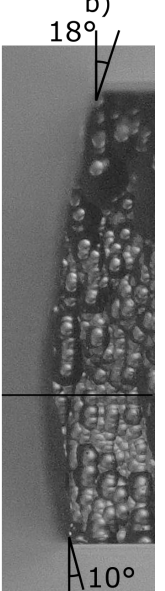

Fig. 2. Light microscopy cross sections of permanent in-volume modifications in glass (a) follow the expected curved trajectory. Corresponding deposited energy densities in the focal plane (insets) obtained from numerical simulations confirm a higher confinement of deposited energy for long pulses. Result of cutting a a $525 \mu \mathrm{m}$ thick glass sheet by perforation with an Airy beam and subsequent etching is shown in (b). The cross section view parallel to the line of laser modifications shows the curved profile of the cut.

For this first demonstration of using the Airy beam for glass cutting we placed the vertex of the parabolic trajectory below the center of the glass sheet to compensate the preferential energy deposition in front of the linear focus (Fig. 2 a)/b)). In a future experiment we plan to shift the intensity distribution with respect to the vertex of the parabola [8] to achieve a more symmetric edge.

\section{References}

1. K. Mishchik, R. Beuton, O. Dematteo Caulier, S. Skupin, B. Chimier, G. Duchateau, B. Chassagne, R. Kling, C. Hönninger, E. Mottay, and J. Lopez. Improved laser glass cutting by spatio-temporal control of energy deposition using bursts of femtosecond pulses. Optics Express, 25(26):33271, 2017.

2. M. Jenne, D.1 Flamm, K. Chen, M. Schäfer, M. Kumkar, and S. Nolte. Facilitated glass separation by asymmetric bessel-like beams. Optics Express, 28(5):6552-6564, 2020.

3. A. Mathis, F. Courvoisier, L. Froehly, L. Furfaro, M. Jacquot, P. A. Lacourt, and J. M. Dudley. Micromachining along a curve: Femtosecond laser micromachining of curved profiles in diamond and silicon using accelerating beams. Applied Physics Letters, 101(7):071110, 2012.

4. P. Polynkin, M. Kolesik, J. V. Moloney, G. A. Siviloglou, and D. N. Christodoulides. Curved plasma channel generation using ultraintense airy beams. Science, 324(5924):229-232, 2009.

5. David Sohr, Jens Ulrich Thomas, and Stefan Skupin. Shaping convex edges in borosilicate glass by single pass perforation with an airy beam. Optics Letters, 46(10):2529-2532, 2021.

6. O. Dematteo Caulier, K. Mishchik, B. Chimier, S. Skupin, A. Bourgeade, C. Javaux Léger, R. Kling, C. Hönninger, J. Lopez, V. Tikhonchuk, and G. Duchateau. Femtosecond laser pulse train interaction with dielectric materials. Applied Physics Letters, 107:181110, 2015.

7. J. Gottmann. Microcutting and hollow $3 \mathrm{~d}$ microstructures in glasses by in-volume selective laser-induced etching (isle). Journal of Laser Micro/Nanoengineering, 8(1):15-18, 2013.

8. Y. Hu, G. A. Siviloglou, P. Zhang, N. K. Efremidis, D. N. Christodoulides, and Z. Chen. Self-accelerating airy beams: Generation, control, and applications. In Zhigang Chen and Roberto Morandotti, editors, Nonlinear Photonics and Novel Optical Phenomena, volume 170 of Springer Series in Optical Sciences, pages 1-46. Springer New York, New York, NY, 2012. 